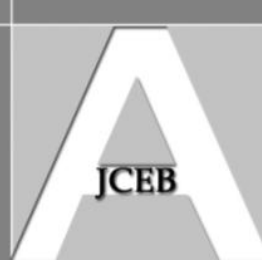

\title{
Assessing Occupant Comfort in an Iconic Sustainable Education Building
}

Rick Best and Brian Purdey, (Bond University, Australia)

\begin{abstract}
The building that houses the Mirvac School of Sustainable Development at Bond University is the first educational building to achieve a six Green Star rating from the Green Building Council of Australia. It has won numerous awards since opening in August 2008 including being judged the RICS (Royal Institution of Chartered Surveyors) Sustainable Building of 2009. After more than two years in use a post-occupancy evaluation study was carried out to assess the performance of the building from the viewpoint of the users; both resident staff and transient students. Results for factors such as lighting, thermal comfort, noise and air quality were compared to benchmarks established by the Usable Buildings Trust. The evaluation also assessed the occupants' perceptions of the building's impact on their own productivity. Users generally find the building provides a comfortable work environment although a number of areas of performance were noted as posing some concerns. These included intrusive noise in some parts of the building and some issues with glare in daylit teaching spaces. Such concerns were found to be in accord with the results of previous studies and they highlight some recurrent problems in "green" buildings designed to maximise the use of natural ventilation and natural light. These design challenges and how occupant satisfaction is to be measured and benchmarked are also discussed in the context of this comparative building study.
\end{abstract}

Keywords: Green building, Post occupancy evaluation, Education facility, Usable Buildings

\section{Introduction}

It seems obvious that any manufactured product, whether a car, a television or a building, would be tested in use to see if it works well. Buildings, although very expensive products, tend to be one-off creations so unlike cars and televisions they are seldom tested, redesigned and refined in the way that mass produced items are. It could be argued, however, that as each building is individually designed that feedback from completed buildings, particularly those of similar function located in comparable environments (geographical, social, financial and so on) would routinely be sought in order to inform the design of subsequent buildings and thus to improve these designs. In reality this is not the case and good buildings often go unnoticed while poor building performance is often not publicised (Leaman et al., 2010). The result is that the same mistakes are repeated and the process of improvement that occurs in manufacturing is seldom duplicated in the design and construction of buildings.

The advent of green buildings in recent years has seen some major changes in the way base buildings are designed with much greater emphasis on energy efficiency, material choice and water usage. These new designs have also provided opportunities to create different built environments - workspaces which emphasise quality as well as cost performance criteria (Vischer, 2008).

Understanding how satisfied occupants are with the workspaces they occupy has underpinned post occupancy evaluation of buildings since the 1980's (Marans and Spreckelmeyer, 1982; Oldham and Rotchford, 1983; Ornstein, 1999). But with the advent of green buildings there has been a renewed interest in the satisfaction of occupants of these buildings. There is some evidence that greener buildings enhance satisfaction, reduce 
absenteeism or sick leave and promote improved productivity as a result of the improved internal environment conditions (e.g. Romm and Browning, 1994; Paul and Taylor, 2008; Armitage et al., 2011).

However, based on user assessments, not all green buildings perform well, while others are rated better than conventional ("non-green") buildings (Edwards, 2006). Leaman et al. (2007) in their Australian comparison of 22 "green design intent" buildings and 23 conventional buildings found that the most comfortable green buildings in terms of noise, temperature, air and lighting, were rated better than any of the conventional buildings. Conversely the buildings that were most poorly rated were also green buildings. Leaman and Bordass (2007) found similar results in their review of 177 UK buildings. These results point to the challenges in translating building design intent into occupant satisfaction given the likelihood that there will be other influencing factors. When green buildings work well they work very well but when, for whatever reason, predicted building performance is not realised in use then the occupants express dissatisfaction.

Murugan and Kato (2010) carried out a limited comparison of two conventional buildings and the one green building on the Bond University campus (the Mirvac building) and found that the green building scored better in regard to nearly all the factors included in their survey which included temperature, lighting, incidence of fatigue, headaches and colds and general satisfaction with the workplace.

\section{The Mirvac School of Sustainable Development}

The Mirvac School of Sustainable Development at Bond University is located on the Gold Coast in Queensland, Australia (Bond, 2011). The climate in the region is described as "humid sub-tropical" (DERM, 2010) with hot, humid summers and mild to cool winters. The Mirvac School comprises two buildings opened in August 2008 that are generally considered as a single unit having been designed and built together. The building received the RICS sustainability design award in 2009 and achieved a six Green Star (Design) rating (GBCA, 2011), the first education building in Australia to receive this top rating (Best, 2010).

The main building has three floors with teaching spaces at ground level and offices, meeting and utility rooms on the upper floors. The smaller building, known as The Living Lab, is a single storey building that is used for meetings, seminars and occasional teaching.

A sophisticated building management system (BMS) controls various building functions including switching to natural ventilation mode when external conditions (temperature and humidity) are such that $100 \%$ outside air can be utilised. Most spaces have manually operated windows and individually switched ceiling fans that can be operated independent of the air conditioning system which is available in enclosed offices via individual occupant controlled units and other spaces such as teaching studios and the Living Lab on an asneeded basis. Most of the artificial lighting in the building is controlled by movement and lighting level sensors.

\section{Research Method}

The concept of green building design and the techniques used are still relatively new, every green building is, to some extent, a prototype as different design concepts are tested in use. In order to increase our understanding of what works best in practice and to improve future designs it is important that newly constructed buildings are formally scrutinised. To this end a detailed post occupancy evaluation (POE) was carried out in mid-2011 to gather information from the users' perspective on the performance of the Mirvac School building.

The evaluation separated building users into two groups: resident users (staff and researchers who occupy office space in the building) and transient users (students) and

Best, R and Purdey, B (2012) 'Assessing occupant comfort in an iconic sustainable education building', Australasian Journal of Construction Economics and Building, 12 (3) 55-65 
applied the paper based BUS Methodology 2 page Occupant Questionnaire 2011 Workplace with Response instrument (UBT, 2011) developed by the Usable Buildings Trust (UBT) in the UK. The BUS methodology has been in use for over 20 years having been developed and refined over time and is supported by an extensive database with benchmarks, possibly useful for comparison purposes.

The survey questionnaire covers a variety of factors related to occupant satisfaction. It is not limited to indoor environment factors such as thermal comfort and noise intrusion but includes general questions regarding the occupants' perception of the building (e.g. image, safety, cleaning, availability of meeting rooms) and operational issues such as speed and effectiveness of responses to problems related to building use (adjustments to temperature and lighting for example). To achieve higher response rates UBT recommended using a paper-based survey questionnaire which was hand delivered to staff and students over a period of two weeks in June 2011. Staff who were away from the university during the survey period were given the option of completing an online version to maximise responses.

Respondents rated their level of satisfaction with the various building attributes, generally on a seven point Likert type scale. Some questions provided the opportunity for respondents to add written comments.

\section{Key Findings}

A total of 85 survey responses were collected; 50 were transient users and 35 resident users. This represents an overall response rate of around $20 \%$ of the total number of regular building users which is at an acceptable level. Survey results were processed by the Usable Buildings Trust as part of the licence agreement. The consolidated results for the whole sample and those for the two distinct user groups are summarised in Table 1.

Assessment of occupant comfort using the BUS methodology relates to functional comfort (Vischer, 2007) and the overlapping concepts of occupant satisfaction with the built environment and its possible impact on work performance. Occupant comfort is addressed in the survey through questions relating to four basic parameters (air, lighting, noise and temperature) and an overall comfort question.

Each comfort parameter is rated using three types of seven point scale with 4 being the neutral mid-point. A type scales have best results at the high point (i.e. a score of 7), B type scales are centred with the best result at the midpoint (i.e. a score of 4 ) while $C$ scales have the best result at the lower end (i.e. a score of 1 ).

Occupants also rate their perception of self-assessed productivity impact on a nine point Likert type scale (from 1 = productivity decreased by $40 \%$ or more, to $9=$ productivity increased by $40 \%$ or more), in $10 \%$ increments.

To simplify interpretation, the BUS methodology also colour categorises results for each parameter as "red" signifying a problem area, "amber" as a potential problem and "green" to indicate a satisfactory result. The colour code is determined statistically by comparing the Mirvac building's mean score for each variable (e.g. Air in summer) against the average score for the last 60 buildings surveyed by BUS (Leaman, 2011). In this case the average scores are for other Australian buildings.

Using this colour categorisation the Mirvac building study, in relation to occupant comfort, returned 15 satisfactory results (green) including Overall comfort, nine potential problem areas (amber) and three clear problem areas (red). 


\section{Indoor Air Quality}

Air quality in the building is generally well regarded by occupants with mean scores for overall perceptions of air quality in both winter and summer greater than 5 . Air in summer was the only variable to be rated "red", while Air in winter was the only other variable in this section not to be rated "green". Occupants perceived the air to be a little humid in summer and a little dry in winter.

\begin{tabular}{|c|c|c|c|c|c|}
\hline Parameter & Residents & Transients & All users & Scale type and range & Rating \\
\hline \multicolumn{6}{|l|}{ Air in summer } \\
\hline dry/humid & 4.88 & 4.28 & 4.54 & B 1: dry - 7: humid & Red \\
\hline fresh/stuffy & 3.24 & 3.54 & 3.45 & C 1: fresh - 7: stuffy & Green \\
\hline odourless/smelly & 2.81 & 2.85 & 2.85 & C 1: odourless - 7: stuffy & Green \\
\hline still/draughty & 4.13 & 3.89 & 3.99 & B 1: still - 7: draughty & Green \\
\hline overall & 4.94 & 5.13 & 5.06 & $\begin{array}{l}\text { A 1: unsatisfactory - } \\
7: \text { satisfactory }\end{array}$ & Green \\
\hline \multicolumn{6}{|l|}{ Air in winter } \\
\hline dry/humid & 3.62 & 3.68 & 3.66 & B 1: dry - 7: humid & Amber \\
\hline fresh/stuffy & 2.62 & 3.28 & 3.01 & C 1: fresh - 7: stuffy & Green \\
\hline odourless/smelly & 2.68 & 2.72 & 2.72 & C 1: odourless - 7: stuffy & Green \\
\hline still/draughty & 4.12 & 3.72 & 3.89 & B 1: still - 7: draughty & Green \\
\hline overall & 4.82 & 5.27 & 5.11 & $\begin{array}{l}\text { A 1: unsatisfactory - } \\
\text { 7: satisfactory }\end{array}$ & Green \\
\hline \multicolumn{6}{|l|}{ Lighting } \\
\hline artificial light & 3.79 & 4.02 & 3.93 & B 1: too little - 7: too much & Green \\
\hline glare from lights & 2.97 & 3.77 & 3.45 & C 1: none - 7: too much & Amber \\
\hline natural light & 4.24 & 4.40 & 4.33 & B 1: too little - 7: too much & Amber \\
\hline $\begin{array}{r}\text { glare from sun and } \\
\text { sky }\end{array}$ & 3.76 & 3.54 & 3.64 & C 1: none - 7: too much & Amber \\
\hline overall & 5.09 & 5.29 & 5.23 & $\begin{array}{l}\text { A 1: unsatisfactory - } \\
\text { 7: satisfactory }\end{array}$ & Amber \\
\hline \multicolumn{6}{|l|}{ Noise } \\
\hline $\begin{array}{l}\text { noise from } \\
\text { colleagues }\end{array}$ & 4.35 & 3.96 & 4.12 & B 1: too little - 7: too much & Green \\
\hline $\begin{array}{r}\text { other noise from } \\
\text { inside }\end{array}$ & 3.85 & 3.77 & 3.81 & B 1: too little - 7: too much & Red \\
\hline $\begin{array}{r}\text { unwanted } \\
\text { interruptions }\end{array}$ & 4.18 & 3.66 & 3.85 & $\begin{array}{l}\text { C 1: not at all - 7: very } \\
\text { frequently }\end{array}$ & Amber \\
\hline noise from outside & 4.85 & 4.33 & 4.53 & B 1: too little - 7: too much & Red \\
\hline overall & 4.97 & 5.06 & 5.04 & $\begin{array}{l}\text { A 1: unsatisfactory - } \\
\text { 7: satisfactory }\end{array}$ & Green \\
\hline \multicolumn{6}{|c|}{ Temperature in summer } \\
\hline hot/cold & 3.31 & 3.80 & 3.60 & B 1: too hot - 7: too cold & Amber \\
\hline stable/varies & 4.45 & 3.46 & 3.88 & B 1: stable - 7: varies during day & Amber \\
\hline overall & 4.88 & 4.72 & 4.77 & $\begin{array}{l}\text { A 1: uncomfortable - } \\
\text { 7: comfortable }\end{array}$ & Green \\
\hline \multicolumn{6}{|l|}{ Temperature in winter } \\
\hline hot $/$ cold & 4.68 & 4.33 & 4.47 & B 1: too hot - 7: too cold & Amber \\
\hline stable/varies & 4.59 & 3.62 & 4.02 & $\begin{array}{l}\text { B 1: stable - 7: varies during } \\
\text { day }\end{array}$ & Green \\
\hline overall & 4.97 & 5.63 & 5.38 & $\begin{array}{l}\text { A 1: uncomfortable - } \\
\text { 7: comfortable }\end{array}$ & Green \\
\hline Comfort overall & 5.77 & 5.60 & 5.69 & $\begin{array}{l}\text { A 1: unsatisfactory - } \\
\text { 7: satisfactory }\end{array}$ & Green \\
\hline
\end{tabular}

Table 1 Mean scores for key comfort parameters

Best, R and Purdey, B (2012) 'Assessing occupant comfort in an iconic sustainable education building', Australasian Journal of Construction Economics and Building, 12 (3) 55-65 


\section{Lighting}

Lighting does not appear to satisfy occupants with the exception of natural lighting. Glare from both external and internal sources is a problem for some, with Glare from lights being one of the few variables to show a substantial difference in perceptions between residents and transients. Lighting overall was perceived by both groups to be acceptable but not completely satisfactory (mean scores: 5.09 for residents and 5.29 for transients).

Occupant comments identified two specific issues of concern. For residents, office lights that are controlled by sensors dim in the late afternoon, or switch off when occupants are at their desks and there is insufficient movement to keep the lights on. For transients a common complaint was the difficulty reading whiteboards, particularly when used as projector screens in the teaching studios.

\section{Noise}

Noise is an area of some concern with two red, one amber and three green ratings. The problem areas identified were Noise from outside and Other noise from inside. The transient users' scores were more favourable across all of the five noise parameters than those of the sedentary users.

\section{Temperature}

Overall temperature in winter and summer returned satisfactory scores (green). The variables Temperature in summer: hot/cold and Temperature in winter: hot/cold were both identified as potential problems, but no temperature parameters were rated in the red category.

\section{Overall Comfort}

The Overall comfort score was a healthy 5.69; this suggests that although there are some concerns in regard to particular aspects of comfort, both resident and transient users are generally comfortable in the building.

The BUS methodology includes the calculation of a Comfort Index and a Forgiveness Index. The Comfort Index is derived from seven key variables: temperature in summer and winter, air in summer and winter, noise, lighting and overall comfort. It is calculated by averaging the $Z$ scores for the seven "overall" comfort variables (Baird et al., 2011). Figure 1 shows the Comfort Index for the Mirvac building (the filled circle) in the context of the Australian comparison buildings; the result shows the building to be in the top $10 \%$ of buildings in the dataset.

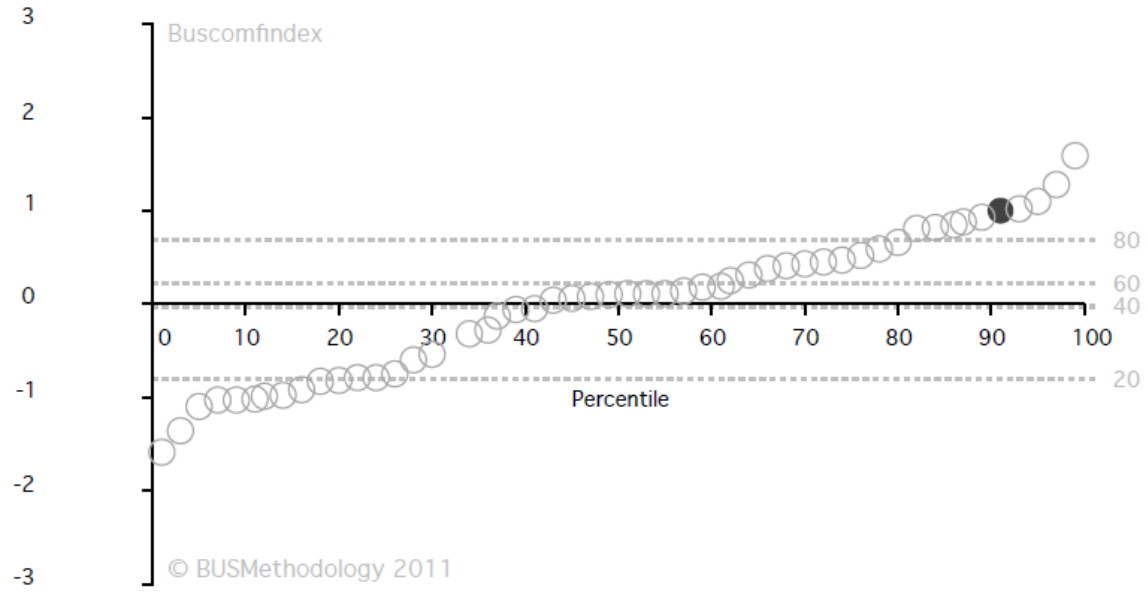

Figure 1 Comfort Index scores for the Mirvac building and the benchmark buildings

Best, R and Purdey, B (2012) 'Assessing occupant comfort in an iconic sustainable education building', Australasian Journal of Construction Economics and Building, 12 (3) 55-65 
The Forgiveness Index is an indicator of how tolerant occupants are of the conditions in a building (Leaman and Bordass, 2007). It is calculated by dividing the mean score for the variable Comfort overall by the average of the mean scores for the variables Temperature in summer overall, Temperature in winter overall, Air in summer overall, Air in winter overall, Lighting overall and Noise overall. Higher values suggest that occupants are more inclined to "forgive" the building if comfort conditions are not exactly as they would prefer. Figure 2 shows the Forgiveness Index for the Mirvac building (the filled circle) in the context of the Australian comparison buildings; the result shows the building to be within the top $15 \%$ of buildings in the dataset and only marginally below those buildings that scored higher for this indicator. While encouraging this result is not particularly significant as the range of scores is quite narrow and it appears that most buildings in the UBT benchmark dataset score similarly for this index.

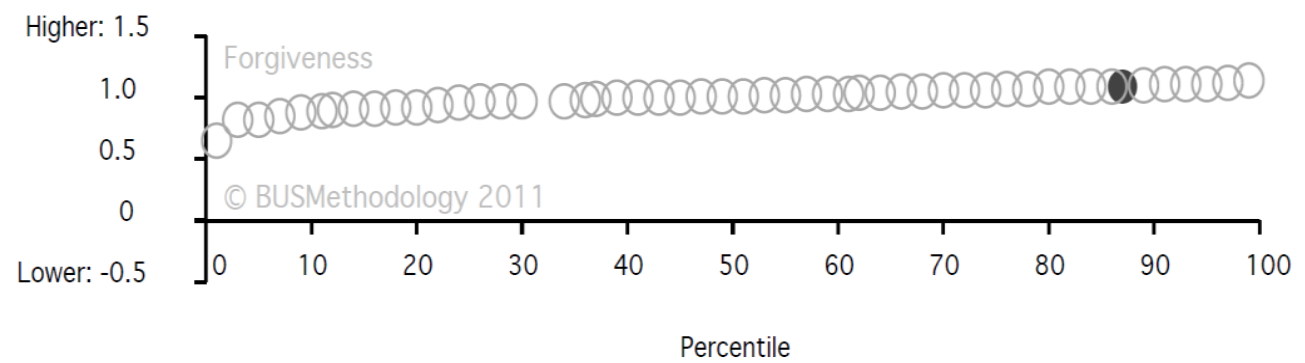

Figure 2 Forgiveness Index scores for the Mirvac building and the benchmark buildings

\section{Benchmarks}

The UBT benchmarks utilised in this study of the Mirvac building are based on the last 60 buildings studied using the BUS methodology. The benchmarks are calculated using a combination of the mean scores and scale midpoints so that a "green" score for any variable indicates performance well above the benchmark (Leaman, 2011). As the benchmarks are based on a rolling data set it is to be expected that as building design improves and more recent buildings are studied and added to the dataset that the benchmarks will rise. Leaman (2010) analysed samples of building data from the periods 1990-1999 and 2000-2008 and concluded that this does appear to be happening.

\section{Discussion}

One of the difficulties in studies such as this is finding suitable benchmarks to measure perceived performance against. Wilkinson et al. (2011) tried to establish benchmarks based on the expectations of respondents who completed their questionnaire. They then compared the same users' perceptions of performance in regard to the various parameters against their prior expectations. Two interesting results emerged. One was that in most cases the average expectation of the users was around 6 on a 7 point scale (where $7=$ "very satisfactory"), suggesting that few users actually expect their workplace conditions to be better than just satisfactory. The second was that with almost every parameter the two target buildings, both described in the paper as "relatively new sustainable office buildings", scored well below the users' fairly modest expectations.

In terms of occupant comfort the Mirvac building was found to perform very well when compared to the UBT benchmarks.

While there are some specific concerns with noise and lighting, the overall scores for these variables were both above 5 , indicating satisfactory performance The Mirvac building is located next to a moderately busy road and on a roundabout that includes a bus stop, these factors contributing to problems associated with noise intrusion from outside the building for both resident and transient users. In their written comments a number of respondents noted that traffic noise does intrude on the side of the building that faces the road and that having 
windows open on that side can interfere with activities such as meetings. The scores for transient users were more favourable across all of the five noise parameters compared with resident users.

At first glance this may appear to be counter-intuitive given that most of the resident users occupy individual offices and thus have the option of closing doors and windows to isolate themselves (acoustically at least) from the rest of the building and the outside world. In fact those who choose this option must rely on their air conditioning unit to supply fresh air and many prefer to have doors and windows open; the trade-off is that they may be exposed for more noise from both inside and outside the building.

Transient users spend less time in the building and so may be less concerned by noise simply because they are not subject to interference on a daily basis. Residents who trade off acoustic comfort for thermal comfort conditions are likely to be more dissatisfied with noise given the evidence that people do not adapt to noise disturbance over time (Witterseh et al., 2004).

Baird (2010) used the UBT survey to gather data from eight buildings in warm-temperate climates in Australia and New Zealand, all of which were considered to be "cutting edge, sustainable buildings". Of the 32 mean scores for the four main noise variables (Noise from colleagues, Noise from other people, Other noise from inside and Noise from outside) 26 were below the mid-point (neutral) score. In Baird's study the mean scores for Noise overall included two buildings below the mid-point, two above the mid-point and four that were neutral, indicating generally satisfactory overall performance. In two instances while the mean scores for the four main variables were below the mid-point the Noise overall mean scores were neutral.

By comparison, all respondents to the Mirvac building survey rated satisfaction with Noise overall above the mid point at 5.04, with only Noise from outside and Other noise from inside being identified as problem areas.

Noise intrusion from outside is a function of the choices individual occupants make regarding a trade off between thermal and acoustic comfort, which is related to green building design.

Noise intrusion becomes a problem because of the ventilation strategy with openable windows and the intent to reduce use of air conditioning in all spaces. This is a particular problem in the Living Lab where it is largely impossible to open the large glass doors on the side facing the roundabout - the trade-off is always to keep the building closed and use the air conditioning or struggle to be heard over the traffic noise during meetings/classes. This problem is, of course, not restricted to the study building but is a major problem for most sustainable buildings, particularly those located in city areas where city noise can be intrusive and prohibits or severely limits the adoption of natural ventilation strategies.

Dissatisfaction with other noise inside the Mirvac building may be related to green design. Residents leaving office doors open to allow natural ventilation expose themselves to noise disturbance from inside the building. One respondent mentioned noise from one of the print (photocopier) rooms, another mentioned noise from work being done by students in the internal courtyard (this is a temporary measure) and one complaint related specifically to the noisy closing of office doors due to the closers on those doors. Several residents, however, commented that simply closing their office doors was sufficient to control noise from inside the building.

Materials choice aimed at reducing embodied energy in partitions may contribute to noise disturbance in classrooms for residents and transients alike. Two transient users commented that the operable walls between the teaching spaces on the ground floor did not block

Best, R and Purdey, B (2012) 'Assessing occupant comfort in an iconic sustainable education building', Australasian Journal of Construction Economics and Building, 12 (3) 55-65 
intrusive sound sufficiently while another suggested that the bells located in an adjacent tower (which chime at 9am, noon and 3pm each day) are "not needed".

These results suggest that while users do note specific noise concerns in green buildings noise problems are not a serious issue overall.

While the Noise overall result was satisfactory, scores for the four specific variables under the lighting heading were adjudged as amber, or problematic These apparent contradictions in noise and lighting are not uncommon. Previous studies (Leaman and Bordass, 2007; Baird et al., 2011) have shown similar results with concerns identified in regard to particular variables but overall scores indicating a reasonably high level of satisfaction.

Leaman and Bordass (2007) suggest that this is due to occupants of green buildings being more tolerant of their buildings' shortcomings; the Forgiveness Index result shown above might support this view. Baird et al.(2011) link this sort of result to the nature of the client organisation; in their study they found that with more or less every building they studied, and they were all buildings that had won awards for sustainable design and/or achieved high ratings using tools such a LEED, BREEAM or Green Star, the client had "a particular commitment to sustainability" and "planned to be the long-term owner-occupier of the building". This is certainly true of the Mirvac building, as it houses the School of Sustainable Development and, being a university building, it is owned, occupied and operated by the university and is expected to be in use for many years.

The perceived problems with variables relating to noise and lighting comfort cannot be ignored even though overall results were good. Leaman and Bordass (2007) note that "[o]ccupants are complaining much more about noise than they used to" and suggest that noise is the major cause of problems in some buildings with natural ventilation or advanced natural ventilation.

Lighting is a recurrent problem in green buildings with designs often intended to maximise use of daylight and provide connection to the outside world for occupants. Armitage et al. (2011) found that "abundant natural light" and "having a view" were two factors that employees liked most in the workplace. Attempts to provide these attributes can often lead to problems with glare from outside and a number of respondents from both groups commented on the problem of intrusive daylight when projectors are in use in teaching spaces. This illustrates another basic problem: the lights in the teaching studios are controlled by sensors so when blinds are down to reduce the incoming daylight the sensors automatically increase artificial light levels. There is no manual switching in these spaces so slide shows and movie projections are difficult to see. Leaman and Bordass (2007) describe situations where blinds (often retrofitted after occupants complain about workspace receiving too much daylight) are often drawn and as a result artificial lights have to be on most of the day. In the Mirvac building where lights are sensor-controlled there is little or no scope for occupants to control the balance between artificial and natural light and this does lead to frustration for users particularly in the teaching spaces.

\begin{tabular}{|c|c|c|c|c|c|c|}
\hline TIME & DEC & JAN & FEB & JUN & JUL & AUG \\
\hline 9am & 67 & 70 & 72 & 69 & 65 & 61 \\
\hline $3 \mathbf{p m}$ & 69 & 70 & 70 & 58 & 55 & 58 \\
\hline
\end{tabular}

Table 2 Monthly average humidity (\%): Gold Coast (BOM, 2011)

The only other problem area identified was for Air in summer: hot/humid, however, all other results in this section were green (including the Air in summer: overall). Humidity is rated higher in summer, and this is to be expected given that in the December-February period average humidity in the area is generally higher than in the June-August period (see Table 2

Best, R and Purdey, B (2012) 'Assessing occupant comfort in an iconic sustainable education building', Australasian Journal of Construction Economics and Building, 12 (3) 55-65 
for average Gold Coast humidity levels) and most of the building is not routinely sealed and air conditioned.

It is not unexpected that staff and students in a School of Sustainable Development would be more inclined to make allowances for factors such as humid conditions in summer and thus rate comfort overall to be good in spite of having to tolerate some periods with humidity above comfortable levels. The relatively high Forgiveness Index result reinforces this view.

\begin{tabular}{|c|c|c|c|c|c|c|}
\hline TEMP & DEC & JAN & FEB & JUN & JUL & AUG \\
\hline Max & 27.7 & 28.6 & 28.5 & 21.3 & 21.1 & 21.8 \\
\hline Min & 20.5 & 21.8 & 21.8 & 13.1 & 12.0 & 12.5 \\
\hline
\end{tabular}

Table 3 Average monthly maximum and minimum temperatures: Gold Coast (BOM, 2011)

Summer temperatures can be moderately high (see Table 3 for monthly average temperatures) and while winters are mild (see Table 3 ) in the month before the survey was conducted (in June and thus during winter) the BMS did have a malfunction with the comfortable temperature somehow resetting to $15^{\circ} \mathrm{C}$; this resulted in the BMS putting the building into natural ventilation mode. This meant that windows in corridors and in the top of the atrium were automatically opened (and could not be manually closed) as well as the air conditioning units being disabled so that occupants had no heating option. For several days the occupants were not able to control the indoor temperature and as this coincided with a period of cool daytime temperatures it is very likely that occupants' perceptions of winter temperature would have been negatively influenced at the time of the survey. In spite of that event the temperature scores were good with no parameters in the red category.

\section{Conclusion}

The study confirms the continuing challenges associated with evaluating and benchmarking occupant satisfaction with comfort conditions in green buildings. The historical evidence is that not all green buildings perform well, while some have been rated better than conventional ("non-green") buildings the buildings most poorly rated by occupants are also green buildings. The results from the Mirvac building survey can only be compared with a rolling data set of buildings with variable green design intent - an "apples versus oranges" comparison with perhaps limited value. This points to the need for further research to develop better evaluation and benchmarking methodologies.

However, in terms of occupant comfort the Mirvac building performs well in its own right and also when compared to the Usable Buildings Trust benchmarks for Australian buildings and those studied in warm-temperate climates. The survey results do identify a handful of specific areas where occupants perceive that there are problems - variables relating to noise, lighting and thermal comfort which cannot be ignored. The study has produced occupant ratings that run generally true to form for green buildings. Scores for summary variables such as Overall comfort were slightly better than specific variables under the same heading, while noise intrusion, lighting quality and sensor control were the problematic areas. Given occupants are complaining much more about work disturbance than they used to, this suggest noise is the major cause of problems in most modern workplaces with naturally ventilated buildings perhaps making further contributions. The results for lighting also point to the complex task of balancing natural light, artificial light and glare in design in order to deliver optimum lighting conditions to a majority of building occupants.

Improved occupant satisfaction and performance may be less about green design intent but occupant knowledge of how to manage the situational constraints presented by this new type of built environment in order to deliver the outcomes required. 


\section{Acknowledgements}

The study was funded by an internal grant for Early Career Researchers offered by the Institute of Sustainable Development and Architecture at Bond University. Judy Doherty assisted with data collection.

\section{References}

Armitage, L., Murugan, A. and Kato, H. (2011) 'Green offices in Australia: a user perception study', Journal of Corporate Real Estate, 13 (3) 169-180

Baird, G. (2010) Sustainable Buildings in Practice: What the Users Think, Routledge

Baird, G., Christie, L., Ferris, J., Goguel, C. and Oosterhoff, H. (2011) 'User perceptions and feedback from the 'best' sustainable buildings in the world', Ecolibrium, June, 30-37

Best, R. (2010) 'Specifying and sourcing materials for a best practice education building', In: Zachar, J., Claisse, P., Naik, T. and Ganjian, E. (eds) Proceedings of Second International Conference on Sustainable Construction Materials and Technologies, June 28-30, Ancona, Italy

BOM (2011) Climate statistics for Australian locations. Gold Coast Seaway. Bureau of Meteorology. http://www.bom.gov.au/climate/averages/tables/cw 040764.shtml

Bond (2011) Facilities: Mirvac School of Sustainable Development www.bond.edu.au/faculties-colleges/institute-of-sustainable-development-architecture/aboutthe-institute/facilities/index.htm

DERM (2010) Queensland Köppen Climate Zones. Queensland Department of Environment and Resource Managemnt www.derm.qld.gov.au/waterwise/plantselector/documents/koppen.pdf

Edwards, B. (2006) 'Benefits of Green Offices in the UK: Analysis from Examples Built in the 1990s', Sustainable Development, 14, 190-2004

GBCA (2011) What is Green Star? Green Building Council of Australia http://www.gbca.org.au/green-star/green-star-overview/ Accessed 19 October 2011.

Leaman, A., Thomas, L. and Vandenberg, M. (2007) 'Green' buildings: What Australian users are saying', EcoLibrium, 6 (10) (November) 22-30, Australian Institute of Refrigeration, Air Conditioning and Heating (AIRAH)

Leaman, A. and Bordass, B. (2007) 'Are users more tolerant of 'green' buildings?', Building Research and Information, 35 (6) 662-673

Leaman, A. (2010) 'Are buildings getting better?', Arup Journal, 1/2010, 4-8

Leaman, A., Stevenson, F. and Bordass, B. (2010) 'Building evaluation: practice and principles', Building Research and Information, 38 (5) 564-577

Leaman, A. (2011) Personal e-mail communication: 18 October.

Marans, R. W. and Spreckelmeyer, K. F. (1982) 'Measuring Overall Architectural Quality - A component of building evaluation', Environment and Behaviour, 14 (6), 652-670

Murugan, A. and Kato, H. (2010) Is it worthwhile going green? Unpublished internal report, Bond University

Oldham, G. R. and Rotchford, N. L. (1983). Relations between office characteristics and employee relations; A study of the physical environment. Administrative Science Quarterly, 28, 542-556.

Ornstein, S. W. (1999). 'A postoccupancy evaluation of workplaces in Sao Paulo, Brazil', Environment and Behavior, 31 (4), 435-462

Paul, W. and Taylor, P. (2008) 'A comparison of occupant comfort and satisfaction between a green building and a conventional building', Building and Environment, 43 (11) 1858-1870

Best, R and Purdey, B (2012) 'Assessing occupant comfort in an iconic sustainable education building', Australasian Journal of Construction Economics and Building, 12 (3) 55-65 
Romm, J. and Browning, W. (1994) Greening the building and the bottom line, Rocky Mountain Institute, Snowmass, Colorado

UBT (2011) Usable Buildings Trust - Portfolio http://www.usablebuildings.co.uk/fp/index.html Vischer, J. C. (2007) 'The concept of environmental comfort in workplace performance', Ambiente Construido, 7 (1), 21-34

Vischer, J. C. (2008) 'Towards an Environmental Psychology of Workspace: How People are Affected by Environments for Work', Architectural Science Review, 51 (2), 97-108

Weatherzone (2011) Gold Coast Climate

http://www.weatherzone.com.au/climate/station.jsp?lt=site\&lc=40764 Viewed: 17 October 2011

Wilkinson, S., Reed, R. and Jailani, J. (2011) 'User Satisfaction in Sustainable Office Buildings: A Preliminary Study', In: Proceedings: $27^{\text {th }}$ PRESS Conference, Gold Coast, 1619 January

Witterseh, T., Wyon, D. and Clausen, G. (2004) 'The effects of moderate heat distress and open-plan office noise on SBS symptoms and on the performance of office work', Indoor Air, $14,30-40$

Zhang, Y. and Altan, H. (2011) 'A comparison of the occupant comfort in a conventional high rise office block and a contemporary environmentally-concerned building', Building and Environment, 46 (2), 535-545 